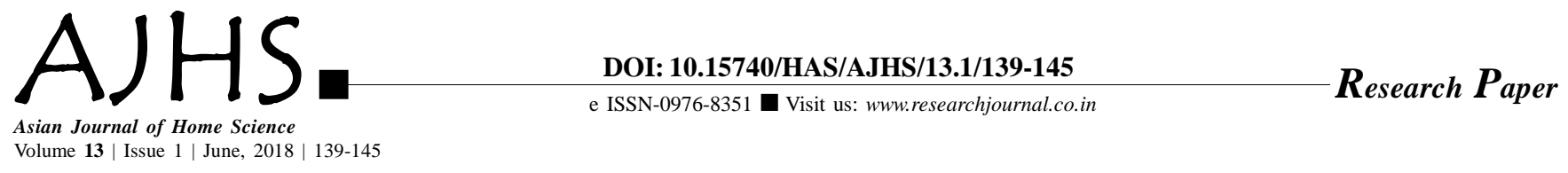

\title{
Utilisation of Himalayan Nettle plant waste for development of innovative union fabrics
}

Neha Garg, Kanwaljit Kaur Brar and Harinder Kaur Saggu

Received: 17.11.2017; Revised: 29.03.2018; Accepted: 16.04.2018

See end of the paper for authors' affiliations

\section{Neha Garg}

Department of Apparel and

Textile Science, College of Home

Science, Punjab Agricultural

University, Ludhiana (Punjab)

India
ABSTRACT : Nettle or Bicchu buti grows abundantly as wild plant in Chamoli and Uttarkashi in Uttarakhand. Very soft and warm nettle fibres are obtained from its bark. Only limited product line of pure nettle fabric was available in the market at a high cost. Thus, the need was felt to diversify the nettle usage and develop innovative textile textures. Thus, present study was conducted to develop eighteen nettle union fabric textures using three selected yarns viz., cotton $(2 / 20,2 / 24)$, acrylic $(2 / 24,2 / 32)$ and polypropylene $(2 / 120$, single ply) as warp along with nettle $(6 \mathrm{Nm})$ yarn in weft direction in plain, basket, and twill weaves. Developed union fabrics were shown to a sample of 180 women in the age group of 25-35 years to assess their preferences for product development from union fabrics. Developed union fabrics were most preferred for jackets, stoles and various home textile products. Cotton $(2 / 20) /$ nettle $(6 \mathrm{Nm})$ with EPI=48, PPI=26 was preferred 41.67 per cent respondents for jacket, while 51.67 per cent respondents preferred acrylic $(2 / 32) /$ nettle $(6 \mathrm{Nm})$ with $\mathrm{EPI}=65$, PPI=34 for stole. Developed union fabrics were comparatively cheaper as cost of cotton, acrylic and polypropylene was nearly 20 per cent of the nettle cost.

KEY WORDS: Nettle, Union fabrics, Weaves, Preferences

- HOW TO CITE THIS PAPER : Garg, Neha, Brar, Kanwaljit Kaur and Saggu, Harinder Kaur (2018). Utilisation of Himalayan Nettle plant waste for development of innovative union fabrics. Asian J. Home Sci., 13 (1) : 139-145, DOI: 10.15740/HAS/AJHS/13.1/139-145. Copyright@ 2018: Hind Agri-Horticultural Society. 